\title{
Роль Франции в установлении мира на Южном Кавказе (в контексте армяно-азербайджанского Нагорно-Карабахского конфликта)
}

\author{
Мустафаева Шафаг, Институт Философии Национальной академии наук Азербайджана
}

Отмечено, что в результате распада СССР Азербайджан снова восстановил свою государственную независимость, положил основу нового этапа и направления в отношениях между Францией и Азербайджаном. Взаимоотношения одновременно начали развиваться в многостороннем формате. Сформировались новые направления сотрудничества между двумя странами. Франция является сопредседателем в Минской группе ОБСЕ, занимающейся вопросом мирного урегулирования Нагорно-Карабахского конфликта. Основная цель статьи - исследование интересов и роль Франции в урегулировании и решении армяно-азербайджанского Нагорно-Карабахского конфликта. Исследование анализирует взаимосвязь политических факторов с геополитическими факторами, изучает конфликт из общей призмы этих факторов. Статья основана на источниках информации разных государств, международных правительственных и неправительственных организаций, имеет четкую структуру и сильную аналитическую и методологическую базу.

После восстановления государственной независимости Азербайджана создание и развитие отношений со странами Европы превратилось в приоритет его внешней политики. Отношения Азербайджана и Франции начали развиваться на новом этапе. Франция сопредседательствует в Минской группе ОБСЕ, занимающейся вопросом мирного урегулирования конфликта Армении и Нагорного Карабаха. Франция также играет активную роль в сотрудничестве между Европейским Союзом и Азербайджаном в рамках Европейской политики соседства.

Ключевые слова: Нагорно-Карабахский конфликт; Армения; Азербайджан; ОБСЕ; Минская группа; мир; Франция

\section{The role of France in establishing peace in the South Caucasus (in the context of the Armenian-Azerbaijani Nagorno-Karabakh conflict)}

\section{Mustafaeva Shafag, Institute of Philosophy of the National Academy of Sciences of Azerbaijan}

The article mentions that after the collapse of Soviet Union of Socialist Republics Azerbaijan regained its independency and founded new stage and trends of the relations between Azerbaijan and France. Mutual relations simultaneously continued to develop on multilateral level. New partnership trends have been ongoing between these two countries. France is a co-chairman of the OSCE Minsk Group which is engaged in peaceful solving of Nagorny Karabakh conflict. Main objective of the article is to research the role and interests of France in regulating and solving the ArmeniaAzerbaijan, Nagorny Karabakh conflict. The paper analyses mutual relations of political factors with geopolitical issues and researches the conflict in coherence from the perspective of these factors. The paper constitutes specific structure and broader analytic-methodological basis through referring to the information sources of different countries, international governmental and non-governmental organizations. Relations between Azerbaijan and France have a long history. Even since the XII-XIV centuries between the two countries, there were different cultural, political and trade relations.

After the restoration of Azerbaijan's state independence, the creation and development of relations with European countries became the priority of its foreign policy. Relations between Azerbaijan and France began to develop at a new stage.

France presides over the OSCE Minsk Group, which deals with the peaceful settlement of the conflict between Armenia and Nagorno-Karabakh. France also plays an active role in the cooperation between the European Union and Azerbaijan within the framework of the European Neighborhood Policy. France has political, economic and cultural relations with Azerbaijan and Georgia. French companies Elf Akiten and Total participate in the use of oil and gas reserves. As co-chairman of the OSCE Minsk Group, France participates in the settlement of the Armenian-Azerbaijani Nagorno-Karabakh conflict, but demonstrates sufficient indecision.

Keywords: Nagorno-Karabakh conflict; Armenia, Azerbaijan; OSCE; Minsk Group; peace; France

\section{Роль Франції у встановленні миру на Південному Кавказі (в контексті вірмено-азербайджанського Нагірно-Карабахського конфлікту)}

\section{Мустафаєва Шафаг, Інститут філософії Національної академії наук Азербайджану}

Відзначено, що в результаті розпаду СРСР Азербайджан знову відновив свою державну незалежність, поклав основу нового етапу і напрямку у відносинах між Францією і Азербайджаном. Взаємовідносини одночасно почали розвиватися в багатосторонньому форматі. Сформувалися нові напрямки співпраці між двома країнами. Франція є співголовою в Мінській групі ОБСЄ, що займається питанням мирного врегулювання Нагірно-Кара- 
бахського конфлікту. Основна мета статті - дослідження інтересів і ролі Франції в урегулюванні і вирішенні вірмено-азербайджанського Нагірно-Карабахського конфлікту. Дослідження аналізує взаємозв'язок політичних чинників з геополітичними факторами, вивчає конфлікт із загальної призми цих факторів. Стаття заснована на джерелах інформації різних держав, міжнародних урядових і неурядових організацій, має чітку структуру і сильну аналітичну та методологічну базу.

Після відновлення державної незалежності Азербайджану створення і розвиток відносин із країнами Свропи перетворилося в пріоритет його зовнішньої політики. Відносини Азербайджану і Франції почали розвиватися на новому етапі. Франція співголовує в Мінській групі ОБСЄ, що займається питанням мирного врегулювання конфлікту Вірменії і Нагірного Карабаху. Франція також відіграє активну роль у співпраці між Свропейським Союзом і Азербайджаном в рамках Європейської політики сусідства.

Ключові слова: Нагірно-Карабахський конфлікт; Вірменія; Азербайджан; ОБСЄ; Мінська група; мир; Франція

$\mathrm{O}$ тношения между Азербайджаном и Францией имеют многовековую историю. Еще начиная с XII-XIV веков, между этими двумя странами существовали разные культурно-политические и торговые отношения. Но в средних веках эти отношения носили беспорядочный и нерегулярный характер.

После восстановления государственной независимости Азербайджана создание и развитие отношений со странами Европы превратилось в приоритет его внешней политики. Отношения Азербайджана и Франции начали развиваться на новом этапе. Франция признала государственную независимость Азербайджана 3 января 1992 года. А дипломатические отношения между двумя странами были установлены 21 февраля 1992 года. 16 марта 1992 года открылось посольство Франции в Азербайджане, а 20 декабря 1994 года - посольство Азербайджана во Франции [3].

Франция сопредседательствует в Минской группе ОБСЕ, занимающейся вопросом мирного урегулирования конфликта Армении и Нагорного Карабаха. Франция также играет активную роль в сотрудничестве между Европейским Союзом и Азербайджаном в рамках Европейской политики соседства. Из Южно-Кавказских республик Франция предпочитала хранить более широкие отношения с Арменией. Связи между двумя странами охватывали экономические, политические и культурные области. В формировании и развитии этих отношений особую роль играла армянская диаспора во Франции. Было известно о проживании боле 500 тысяч армян во Франции [6].

Франция имеет политические, экономические и культурные отношения и с Азербайджаном, и с Грузией. Французские компании «Elf Akiten» и «Total» участвуют в использовании нефтегазовых запасов.

Как сопредседатель Минской группы ОБСЕ, Франция участвует в процессе урегулирования Армяно-Азербайджанского Нагорно-Карабахского конфликта, но демонстрирует достаточную нерешительность.

Движение, начатое армянскими сепаратистами в 1988 году в Нагорно-Карабахской области
Азербайджана, положило начало этническому сепаратизму в бывшей СССР. Армяне, которые на протяжении истории выдвигали против Азербайджана территориальные претензии, на этот раз с помощью М. Горбачева начали широкую деятельность для отрыва Нагорного Карабаха от Азербайджана. Первая искра, воспламенившая Армяно-Азербайджанский Нагорно-Карабахский конфликт, была зажжена именно во Франции. Академик А. Аганбегян, во время встречи с группой французских армян в гостинице «Интерконтинентал» Парижа, сообщил, что является сторонником отдачи Карабаха Армении и заявил: «В связи с этим я выдвинул одно предложение. Надеюсь, что эта проблема найдет свое решение в условиях перестройки и демократии». В то же время в этот период армяне начали вооружаться (члены запрещенной радикальной националистической партии «Дашнакцутюн» (с дашнаками). И. Мурадян, вошедший в связь с их тайными подразделениями за границей и в Ереване, даже купил у них оружие и боеприпасы. Позже это оружие было использовано, чтобы изгнать проживающих в Армении сотни тысяч азербайджанцев с их исторических земель, другими словами совершить в Армении этническую чистку. В результате сначала азербайджанцы полностью были изгнаны из Армении, со своих исторических земель, затем из Нагорного Карабаха. Развитие событий вокруг Нагорного Карабаха в этом направлении, распространение в регионе армянского сепаратизма, террора в конце привело к открытой войне между Арменией и Азербайджаном. В результате войны Армения, которую открыто защищала и которой помогала Россия, оккупировала двадцать процентов территории Азербайджана, один миллион азербайджанцев изгнаны с постоянного места жительства [14, с. 189244].

Еще до начала конфликта, чтобы завоевать поддержку международной общественности, армяне вели серьёзную компанию. Здесь также широко использовались возможности армянского лобби. Между сенатом Франции и армянской лобби в этой стране существовали очень близкие отношения. 
2 марта 1992 года Азербайджанская Республика была принята полноправным членом в $\mathrm{OOH}$ и территория Нагорного Карабаха была принята этой организацией как составная часть Азербайджана. В мае 1993 года, в период расширения агрессии Армении против Азербайджана, Президент Республики Франция Ф. Миттеран в письме Президенту Азербайджанской Республики А. Эльчибеку заявил о том, что «Франция очень обеспокоена по поводу расширения военных действий вокруг Нагорного Карабаха» и отметил, что «Французское правительство выступило на разных уровнях с требованием вывода армянских сил из Кельбаджара». Ф. Миттеран в письме призывал руководство Азербайджана продолжить поиски путей урегулирования конфликта в рамках Минской группы ОБСЕ [2, с. 79]. Совет Безопасности $\mathrm{OOH}$, постоянным членом которого являлась также Франция, в связи с оккупацией армянами Азербайджанских территорий в 1993 году принял резолюции № $822,853,874,884$, в каждом документе указал неприкосновенность признанных на международном уровне границ и недопустимость получения территории с применением силы. 30 января 1992 года Азербайджан и Армения были приняты членами в Совещание по Безопасности и Сотрудничеству в Европе (СБСЕ, с декабря 1994 года ОБСЕ), и урегулирование армяно-азербайджанского Нагорно-Карабахского конфликта было возложено на Минскую группу, созданную на заседании Совета Министров этой организации, проведенном 24 марта в Хельсинки, в состав которой входили Азербайджан, Армения, США, Россия, Турция, Франция, Германия, Италия, Беларусь, Чехия, Словакия и Швеция [14; 189-244]. Но в этот период отношения между Азербайджаном и Францией не были на должном уровне. Одной из причин этого была пропагандистская машина Армении, заинтересованная в формировании взаимного недоверия и холодности во Французско-Азербайджанских отношениях, и проводимые в этом направлении дела армянской диаспоры, выступления отдельных правительственных чиновников во Франции, где армянское лобби имеет сильное влияние, в отношении Азербайджана не о высших интересах этого государства, а об ограниченных этнических интересах армян $[2$, с. 80$]$. Для развития азербайджано-французских отношений существенное значение имел первый официальный визит Президента Азербайджанской Республики Гейдара Алиева во Францию. Свой первый официальный визит в Европу Президент Гейдар Алиев начал с Франции. 19-22 декабря 1993 года во время визита во Францию Президент Гейдар Алиев провел встречи с главой этого государства Франсуа Миттераном и другими должностными лицами. Во время встречи Президент Франции
Франсуа Миттеран объявил, что признает территориальную целостность Азербайджана и неприкосновенность границ, заявил о верности разрешения конфликта в рамках конференции СБСЕ.

1994 года главный секретарь Министерства Иностранных дел Франции Бертран Дюфург приехал в Баку, заявил, что «защищает принцип территориальной неделимости государств» страны и воспользуется всеми возможностями для скорого разрешения Армяно-Азербайджанского конфликта в рамках ОБСЕ. На саммите ОБСЕ, проведенном в декабре 1994 года, было принято решение о создании сопредседательства в Минской группе. С января 1997 года Франция, наряду с США и Россией, начала осуществлять деятельность в качестве сопредседателя Минской группы.

На Лиссабонском саммите ОБСЕ, проведенном в декабре 1996 года, были определены три принципа относительно решения Армяно-Азербайджанского конфликта:

1. Территориальная целостность Армянской Республики и Азербайджанской Республики;

2. Предоставление Нагорному Карабаху самого высокого статуса самоуправления в составе Азербайджана;

3. Обеспечение безопасности всего населения Нагорного Карабаха.

Из участвовавших на Лиссабонском саммите 54 стран, исключая Армению, оставшиеся 53, в том числе Франция, дали согласие на эти принципы и Азербайджанская сторона неоднократно заявляла, что приняла их за основу для последующего этапа мирных переговоров [9, с. 55-60].

На Лиссабонском саммите Франция была в ряде стран, поддерживающих территориальную целостность Азербайджана. В общем после Лиссабонского саммита в 1996 году наблюдалась серьезная борьба за сопредседательство Минской группы ОБСЕ. Так, в этот период сопредседателями Минской группы были Россия и Финляндия, их позиция в большинстве случаев была одинаковой. После напряженных обсуждений сопредседательство Финляндии было заменено на Францию. Но и это в ходе переговоров не служило усилению позиций Азербайджана. Поэтому по инициативе Президента Азербайджана Гейдара Алиева на повестку дня встал вопрос о становлении США сопредседателем. Хотя Армения и Россия серьезно сопротивлялись этому, в феврале 1997 года заместитель госсекретаря США Строуб Телботт был назначен на должность сопредседателя Минской группы ОБСЕ. Таким образом, с 1 января 1997 года Российская Федерация, Франция и США назначены сопредседателями Минской группы ОБСЕ [10, с. 240].

После избирания Франции сопредседателем с целью урегулирования армяно-азербайджанского 
Нагорно-Карабахского конфликта Минская группа в 1997-1998-х годах выдвинула три предложения. Из этих предложений «Решение пакета», представленное в июле 1997 года состояло из двух соглашений, включенных в один пакет. Первое Соглашение предусматривало приостановление вооруженного конфликта, второе - определение статуса Нагорного Карабаха. Было рекомендовано вывести вооруженные силы в два этапа. На первом этапе силы, расположенные вдоль нынешней линии соприкосновения к востоку и югу от Нагорного Карабаха, отступают назад на несколько километров к согласованным линиям, в это время расположить передний отряд многотысячной силы ОБСЕ в первоначальном порядке в обоснованной с военной точки зрения буферной зоне, разделить стороны вдоль этой линии и на втором этапе вывода войск, с целью обеспечения безопасности, должным образом принять во внимание рекомендации группы планирования высокого уровня. На втором этапе армянские силы уводятся в пределы Армянской Республики, силы Нагорного Карабаха возвращаются в пределы Нагорно-Карабахской Автономной Области от 1988 года, Азербайджанские силы на основании рекомендаций группы планирования высокого уровня отступали на согласованные линии. А во втором Соглашении, называемом Статус Нагорного Карабаха, в качестве основного принципа указано признание территориальной целостности и неприкосновенность границ Азербайджана и Армении. По этому документу Нагорный Карабах является государственным и территориальным образованием в составе Азербайджана, и определение его судьбы возможно после оформления в соглашении между органами власти Азербайджанской Республики и Нагорного Карабаха одобрения со стороны Минской группы, инкорпорации в конституции Азербайджана и Нагорного Карабаха. А при наличии такого соглашения Нагорный Карабах и Нахичевань получили бы право свободно, беспрепятственно поддерживать транспортную и коммуникационную связь с Арменией и Азербайджаном. Кроме этого, административные границы Нагорного Карабаха должны были быть установлены по границам бывшей Нагорно-Карабахской Автономной Области. В проекте соглашения была также указана возможность существования конституции Нагорного Карабаха. Но эта конституция на основании этого документа должна была сделать официальную инкорпорацию соглашения между органами власти Нагорного Карабаха и Азербайджаном о форме определения своей судьбы. В документе нашло свое отражение то, что Нагорный Карабах имеет свою законодательную власть, содержит национальную гвардию. Все вопросы должны были решаться в рамках территориаль- ной целостности Азербайджана, и по этой причине Баку принял это предложение. В целом реакция Армении на предложение тоже была положительной, но из-за отрицательного отношения сепаратистов Нагорного Карабаха, его осуществить не удалось. В сентябре 1997 года Минская группа выдвинула свое второе предложение, называемое «Решение этапа». Этот документ предусматривал регулирование конфликта на двух этапах. На первом этапе оккупационные войска должны были отступить, в регионе расположить миротворные войска, беженцев возвратить, блокаду Армении устранить, на втором этапе должен был быть решен вопрос Лачина, объединяющего Нагорный Карабах с Арменией, определен окончательный статус Нагорного Карабаха. Несмотря на то, что Азербайджан и Армения приняли это предложение, Нагорный Карабах отверг его [1].

Наконец, в ноябре 1998 года сопредседателями конфликтующим сторонам был представлен третий вариант решения. Это опять был вариант «Пакет решений» и его основу составляла концепция «общее государство». Согласно этому предложению, Нагорно-Карабахскому региону Азербайджана должен быть присвоен статус государственной и территориальной единицы в форме республики и он должен был составлять общее государство вместе с Азербайджаном в рамках признанных на международном уровне границ Азербайджана [10, с. 247-248]. Суть предложения заключалась в создании конфедерации, состоящей из двух государств - Азербайджана и Нагорного Карабаха, имеющих равные права, свою конституцию, вооруженные силы и правоохранительные органы, не вмешивающихся в дела друг друга [1]. Несмотря на то, что сепаратистский режим Армении и Нагорного Карабаха принял это предложение, принимая во внимание его противоречие суверенитету Азербайджана принципам Лиссабонского саммита, Азербайджан отверг этот вариант. После того, как план Минской группы «общее государство» потерпел неудачу, мирным переговорам был дан перерыв. Начиная с 1999 года, начали проводиться двусторонние встречи президентов Азербайджана и Армении через посредничество США, России, Франции и др. стран, но даже в этом формате переговоров не удалось найти вариант для прекращения конфликта [1]. Убийство ряда влиятельных политиков, включая Главного министра Армении Вазгена Саркисяна и председателя парламента Карена Демирчяна в результате теракта 27 октября 1999 года в парламенте Армении, помешало реализации документа, предусмотренного подписать на саммите ОБСЕ в Стамбуле 18-19 ноября 1999 года [5, с. 269, 272].

В январе 2001 года по инициативе Жака Ширака во Франции начался новый этап переговоров 
между главами государств Азербайджана и Армении. Парижские переговоры между президентами были уже 14-й встречей. Хотя на встрече велись серьезные обсуждения по поводу разрешения конфликта, конкретного результата не добились. Однако, и президенты Азербайджана и Армении, и глава государства Франции Жак Ширак выступили с заявлением, выражающим необходимость продолжения диалога, подчеркнули последующее продолжение усердий для получения компромисса между сторонами. Последующая встреча президентов во Франции 3 марта по инициативе Жака Ширака создала впечатление о близости дня подписания мирного соглашения. Из-за того, что и президенты в своих заявлениях отдавали большее предпочтение оптимистичным нотам, возможность продвижения в разрешении Армяно-Азербайджанского Нагорно-Карабахского конфликта казалась реальной. Несмотря на это, единственная общая позиция президентов предусматривала принцип продолжения переговоров и увеличение активности в этом направлении [12, с. 73].

В ноябре 2002 года Гейдар Алиев и Жак Ширак, которые встретились и на Пражском саммите Совета Евро-Атлантического Партнёрства НАТО, обсудили вопрос урегулирования Нагорно-Карабахского конфликта. Жак Ширак пообещал Гейдару Алиеву продолжить посредническую деятельность. В феврале 2006 года во дворце Рамбуйе близ Парижа при участии сопредседателей Минской группы ОБСЕ состоялась очередная встреча главы Азербайджанского государства Ильхама Алиева и президента Армении Роберта Кочаряна. Из-за недостигнутого соглашения в вопросе использования средств референдума в урегулировании конфликта этот этап переговоров результатов не дал [1].

С 2004 года в рамках «Пражского процесса» в результате опыта диалога двух президентов, а также министров иностранных дел сформировалось новое предложение мира касательно разрешения конфликта. Три принципа - неприменение силы, территориальная целостность и право народов на самоопределение - и соответствующий документ об основных принципах разрешения Нагорно-Карабахского конфликта, состоящий их шести положений, 29 ноября 2007 года был представлен на Мадридском саммите ОБСЕ конфликтующим сторонам. В рамках заседания министров иностранных дел стран-членов ОБСЕ, состоявшегося 29 ноября 2007 года в Мадриде, сопредседателями Минской группы с целью устранения Азербайджано-Армянского конфликта был выдвинут новый план, основанный на компромиссах. Согласно этому плану Азербайджан и Армения должны гарантировать безопасность и расположение международных миротворцев в зоне конфликта, Ар- мения и Нагорный Карабах вывести свои войска из всех оккупированных территорий окрестности Нагорного Карабаха, с особыми условиями для Кельбаджара и Лачына, депортированное население возвратить в родные места, все транспортные и торговые пути открыть, окончательный статус Нагорного Карабаха установить в конце путем голосования, до этого определить временный статус [14, с. 167].

В августе 2008 года возникшее между Россией и Грузией противостояние создало новое геополитическое положение на Южном Кавказе. В результате глобальные и региональные акторы усилили старания в направлении устранения Нагорно-Карабахского конфликта [4, с. 72]. В Мюнхене 22 ноября 2009 года в здании главного консульства Франции на встрече между Азербайджанским и Армянским президентами Серж Саркисян, продемонстрировав жесткую позицию, снова поднял ранее согласованные вопросы [14, с. 168]. В октябре 2011 года президент Франции Н. Саркози, находясь в Армении, также коснулся вопроса Нагорного Карабаха. На совместной пресс-конференции с президентом Армении в связи с Карабахским конфликтом заявил, что восстановление мирных переговоров ОБСЕ является единственным путем решения в рамках Минской группы: «Мы видим, что для установления мира в связи с этой проблемой, надо достичь точки касания». Саркози заявил, что Южно-Кавказский регион является достаточно нестабильным и с точки зрения развития двух стран важно достичь мира [7].

В 2009-2011 годах президенты стран сопредседателей Минской группы ОБСЕ - Дмитрий Медведев, Барак Обама и Николя Саркози - в саммитах стран «Большой восьмерки» (G-8), проводимых в Аквиле (Италия), Мускоке (Канада) и Довиле (Франция), в совместных заявлениях, связанных c Нагорно-Карабахским конфликтом, заявили, что поддерживают лидеров Азербайджана и Армении. Обновленная версия «Мадридских принципов» была раскрыта общественности именно в декларации, принятой в Аквиле. Подчеркивалось, что подтверждение этих принципов конфликтующими сторонами в заявлениях в будущем может дать возможность подготовки всестороннего мирового соглашения в связи с конфликтом [4, с. 72].

Франция, как страна-сопредседатель Минской группы ОБСЕ, в процессе урегулирования Армяно-Азербайджанского Нагорно-Карабахского конфликта, не всегда соблюдала нейтральность. Во время официального визита Н. Саркози в Азербайджан 7 октября 2011 года президенты Франции и Азербайджана положили основание Французского Лицея в Баку. На церемонии Президент Азербайджана Ильхам Алиев, выступая во всех направлениях отношений Азербайджана и Фран- 
ции, заявил о том, что в будущем отношения будут носить стратегический характер. Президент Ильхам Алиев привлек к центру внимания вопросы, начиная с нефтегазовых проектов до проблемы Нагорно-Карабахского конфликта. Но выступление Президента Саркози в основном охватывало области культуры и образования. Поехав в Москву в 1944 году, он, хотя вспомнил пребывание генерала Франции Шарль де Голля в Азербайджане, но ни слова не произнес о Нагорно-Карабахской проблеме [11]. Одной из интересных черт является то, что Н. Саркози возложил венок перед мемориальным комплексом геноцида в Армении, посетил музей-институт геноцида, внес записи в памятную книгу. Затем президент посадил ель в памятной аллее. Но в Баку не посетил аллею и мемориал, где лежат Азербайджанские шехиды, умерщвленные армянами и армией бывшего СССР. На этой Аллее Шехидов также имеется мемориал с выгравированными именами турецких солдат, спасших Баку от большевистско-дашнакской резни в начале XX века. Президент Франции, который заявил «если Турция не признает геноцид армян, Франция примет законопроект о криминализации отрицания геноцидов», находясь в Азербайджане перед прессой даже не говорил о территориальной целостности Азербайджана, оккупированных территориях Нагорного Карабаха и Азербайджана.

В то же время президент Франции на совместной пресс-конференции с президентом Армении Сержом Саркисяном сказал о том, что надеется на достижение мира между Азербайджаном и Арменией. Он заявил, что возобновление переговоров между армянскими и Азербайджанскими сторонами является единственным путем решения в рамках Минской группы ОБСЕ. 18-19 сентября 2012 года Президент Азербайджана Ильхам Алиев совершил деловой визит во Францию. Президент Ильхам Алиев был принят Президентом Франции Олландом, перспективы «замороженного» Нагорно-Карабахского конфликта были на повестке дня этой встречи [8].

Но продолжение со стороны Армении неконструктивной и оккупационной политики, и совершение армией диверсантских действий на контактной линии, также вдоль армяно-азербайджанской границы, не дало возможности достигнуть продвижения в процессе переговоров. С целью уменьшить это напряжение, по инициативе Президента Российской Федерации Владимира Путина 10 августа 2014 года в Сочи, 4 сентября по инициативе госсекретаря США Джона Керри в Ньюпорте (Уэльсе) и 27 октября по инициативе Президента Франции Франсуа Олланда в Париже были проведены три встречи с участием Ильхама
Алиева и Президента Армении Сержа Саркисяна, также сопредседателей Минской группы ОБСЕ [4, c. 74]. Эти встречи стали причиной достижения определенной положительной динамики между сторонами и уменьшения числа столкновений на границе.

Так, несмотря на все усилия Франции, даже организацию прямой встречи лидеров конфликтующих сторон в Париже по инициативе Жака Ширака, не удалось уклонить Армению от позиции захватчика, вынудить ее освободить Нагорный Карабах и также расположенные вокруг него оккупированные районы. Одной из основных причин этого было то, что Франция и другие страны-сопредседатели, продемонстрировав решительную позицию, не сделали конкретных шагов против страны-оккупанта Армении.

10 марта 2017 года во время визита в Азербайджан делегации, возглавляемой председателем группы французско-кавказской дружбы Сената Французской Республики Андре Рейшаром, Армяно-Азербайджанский Нагорно-Карабахский конфликт стал объектом обсуждения. Министр иностранных дел Э. Мамедъяров предоставил информацию о ведении переговоров в направлении урегулирования Армяно-Азербайджанского Нагорно-Карабахского конфликта, позицию Азербайджана в разрешении конфликта, основанную на нормах международного права и принципов, соответствующие резолюции Совета Безопасности ООН и справедливость. Он заявил, что для урегулирования конфликта в первую очередь необходимо вывести вооруженные силы Армении с оккупированных территорий Азербайджана и возвращение азербайджанских беженцев и вынужденных переселенцев. Министр подчеркнул, что каждому ясен процесс урегулирования конфликта и в этом отношении для продвижения вперед необходимо проявление Арменией политической воли [13].

Во французской прессе в заметной степени увеличилось число аналитических статей о Нагорно-Карабахском конфликте, продолжающемся между Азербайджаном и Арменией в течение нескольких десятилетий и время от времени сопровождающимся кровопролитными событиями. Если это связано, с одной стороны, с тем, что Франция является сопредседателем Минской группы, старающейся урегулировать конфликт мирным путем, то с другой стороны - это истекает из того, что в последние годы правда Азербайджана еще более распространилась во Франции и в результате этого в научных, политических и дипломатических кругах возросло внимание к этому конфликту, оставшемуся не урегулированным уже долгое время. 


\section{БІБІЛІОГРАФІЧНІ ПОСИЛАННЯ}

1. Ermənistan-Azərbaycan, Dağlıq Qarabağ münaqişəsi. - Giriş rejimi: http://files.preslib.az/projects/azerbaijan/ g18.pdf

2. Həsənov Ә.M. Azərbaycanın ABŞ və Avropa dövlətləri ilə münasibətləri (1991-1996) / Ә.M. Həsənov. - Bak1: Elm, 2000. - $368 \mathrm{~s}$.

3. Azərbaycan - Fransa münasibətlərinə dair ümumi tarixi arayış. - Giriş rejimi: http://ocaz.eu/az/azrbaycanavropada/diplomatiya/4182-azrbaycan-fransa-mnasibtlrin-dair-mumi-tarixi-aray.html

4. Azərbaycan Respublikasının xarici siyasətinin əsas istiqamətləri (1991-2016) / Azərbaycan Respublikasının Prezidenti yanında Strateji Araşdırmalar Mərkəzi. - Bakı: «Poliart» MMC, 2017. - 904 s.

5. Мехтиев Р. Нагорный Карабах: история, прочитанная по источникам / Р. Мехтиев. - М.: Аквариус, 2014. $-279 \mathrm{c}$.

6. Fransada soyadını dəyişməyən 500 min erməni yaşayır. - Giriş rejimi: http://sia.az/az/news/politics/598186.html 7. Fransa prezidentinin Cənubi Qafqaz səfəri: təzadlar və müəmmalar. - Giriş rejimi: http://www.voanews.com/ azerbaijani/news/Fransa-prezidentinin-Cnubi-Qafqaz-sfri-tzadlar-v-mummalar---131343128.html

8. Novruz Məmmədov: «Prezident İlham Oliyev dinamik dəyişən qlobal geosiyasi mühitdə Azərbaycanın çevik xarici siyasət yeritməsi zərurətini əsaslandırdı» - Giriş rejimi: http://newtimes.az/az/politics/661

9. Həsənov Ә.M. Lissabon sammiti - 1996 / Ә.M. Həsənov. - Bakı: Azərnəşr, 1997. - 312 s.

10. Qasıml M. Azərbaycan Respublikasının xarici siyasəti (1991-2003). I hissə / M. Qasımlı. - Bak1: Mütərcim, 2015. $-648 \mathrm{~s}$.

11. Səfəroğlu X. Nikola Sarkozi Azərbaycanın ərazi bütövlüyünə dəstək kəlməsi işlətmədi / X. Səfəroğlu // Ayna qəzeti. - 2011. - 08 oktyabr.

12. De Vaal T. «Qara Bağ: Ermənistan və Azərbaycan sülh və savaş yollarında», Bakı: 2008. , 344 səh.

13. № 62/17, Xarici işıır naziri Elmar Məmmədyarov Fransa Respublikası Senatının Fransa-Qafqaz Dostluq Qrupunun sədri Andre Reyşarın başçılıq etdiyi nümayəndə heyəti ilə görüşüb. - Giriş rejimi: http://www.mfa.gov. az/news/878/4760

14. Гасымлы М. Дж. Агрессия Армении против Азербайджана / М. Дж. Гасымлы // От Майендорфа до Астаны: принципиальные аспекты армяно-азербайджанского нагорно- карабахского конфликта. - М., 2010. -552 c.

\section{REFERENCES}

1. Ermənistan-Azərbaycan, Dağlıq Qarabă̆ münaqişəsi [The Armenian-Azerbaijani Nagorno-Karabakh conflict]. Retrieved from: http://files.preslib.az/projects/azerbaijan/g18.pdf [in Azerbaijani].

2. Həsənov, Ә.M. (2000). Azarbaycanin ABŞ və Avropa dövlatlari ila münasibatlari (1991-1996) [Relations of Azerbaijan with the US and European Countries (1991-1996)]. Bak1: Elm [in Azerbaijani].

3. Azarbaycan - Fransa münasibatlarina dair ümumi tarixi araylş [Historical background on Azerbaijan-France relations]. Retrieved from: http:/ocaz.eu/az/azrbaycan-avropada/diplomatiya/4182-azrbaycan-fransa-mnasibtlrindair-mumi-tarixi-aray.html [in Azerbaijani].

4. Azərbaycan Respublikasinın xarici siyasətinin əsas istiqamətləri (1991-2016) [Main Directions of the Foreign Policy of the Republic of Azerbaijan (1991-2016)]. (2017). Azarbaycan Respublikasının Prezidenti yanında Strateji Araşdırmalar Markəzi. Bakı: «Poliart» MMC [in Azerbaijani].

5. Mehdiyev, R. (2014). Nagorno-Karabakh: a story read by sources [Nagorno-Karabakh: a story read by sources]. M.: Aquarius [in Russian].

6. Fransada soyadını dayişməyən 500 min erməni yaşayır [There are 500,000 Armenians living in France who do not change their surname]. Retrieved from: http://sia.az/az/news/politics/598186.html [in Azerbaijani].

7. Fransa prezidentinin Canubi Qafqaz safari: tazadlar vo müammalar [The French President's visit to the South Caucasus: contradictions and mysteries]. Retrieved from: http://www.voanews.com/azerbaijani/news/Fransaprezidentinin-Cnubi-Qafqaz-sfri-tzadlar-v-mummalar---131343128.html [in Azerbaijani].

8. Novruz Mammadov: "Prezident Ilham Oliyev dinamik doyişən qlobal geosiyasi mühitdə Azərbaycanın çevik xarici siyasat yeritmasi zaruratini asaslandırdı» [Novruz Mammadov: "President Ilham Aliyev justified the necessity of Azerbaijan to introduce a flexible foreign policy in a dynamic geopolitical environment»]. Retrieved from: http:// newtimes.az/az/politics/661 [in Azerbaijani].

9. Həsənov, Ә.M. (1997). Lissabon sammiti - 1996 [Lisbon Summit - 1996]. Bakı: Azərnəşr [in Azerbaijani].

10. Qasiml1, M. (2015). Azarbaycan Respublikasinın xarici siyasati (1991-2003). [Foreign Policy of the Republic of Azerbaijan (1991-2003)]. Part I. Bak1: Mütərcim [in Azerbaijani].

11. Səfəroğlu, X. (2011). Nikola Sarkozi Azərbaycanın ərazi bütövlüyünə dəstək kəlməsi işlətmədi [Nicola Sarkozy did not support the territorial integrity of Azerbaijan / X. Safaroglu]. Ayna qazeti [in Azerbaijani].

12. De Vaal, T. (2008). "Qara Bağ: Ermanistan va Azarbaycan sülh va savaş yollarında» [Black Garden: Armenia and Azerbaijan on the Ways of Peace and War]. Bak1 [in Azerbaijani].

13. № 62/17, Xarici işlar naziri Elmar Mommadyarov Fransa Respublikası Senatının Fransa-Qafqaz Dostluq 
Qrupunun sadri Andre Reyşarın başçılıq etdiyi nümayəndə heyəti ilə görüşüb [№ 62/17, Foreign Minister Elmar Mammadyarov met with a delegation led by Chairman of the France-Caucasus Friendship Group of the French Senate Andre Reyshar]. Retrieved from: http://www.mfa.gov.az/news/878/4760 [in Azerbaijani].

14. Gasymly, M.Dzh. (2010). Agressija Armenii protiv Azerbajdzhana [Gasimli M. J. Aggression of Armenia against Azerbaijan]. Ot Majendorfa do Astany: principial'nye aspekty armjano-azerbajdzhanskogo nagorno-karabahskogo konflikta. Moscow [in Russian].

\section{Мустафаева Шафаг}

Докторант, преподаватель

Институт Философии НАНА

AZ1001, Азербайджан, г. Баку, улица Истиглалият, 30

\section{Mustafaeva Shafag}

Doctoral student, lecturer

Institute of Philosophy of the National Academy of Sciences of Azerbaijan

30, Istiglaliyyat str., Baku, AZ1001, Azerbaijan

ORCID: 0000-0001-6277-7761_Ｅmail:rus_ruhimli@yahoo.com

Цитування: Мустафаева Шафаг. Роль Франции в установлении мира на Южном Кавказе (в контексте армяно-азербайджанского Нагорно-Карабахского конфликта) / Шафаг Мустафаева // Науково-теоретичний альманах «Грані». - 2018. - Т. 21. - № 3. - С. 108-115.

Citation: Mustafaeva, Shafag. (2018). Rol' Francii v ustanovlenii mira na Juzhnom Kavkaze (v kontekste armjano-azerbajdzhanskogo Nagorno-Karabahskogo konflikta) [The role of France in establishing peace in the South Caucasus (in the context of the Armenian-Azerbaijani Nagorno-Karabakh conflict)]. Scientific and theoretical almanac "Grani», 21(3), 108-115.

Стаття надійшла / Article arrived: 1.03.2018

Схвалено до друку / Accepted: 6.03.2018 